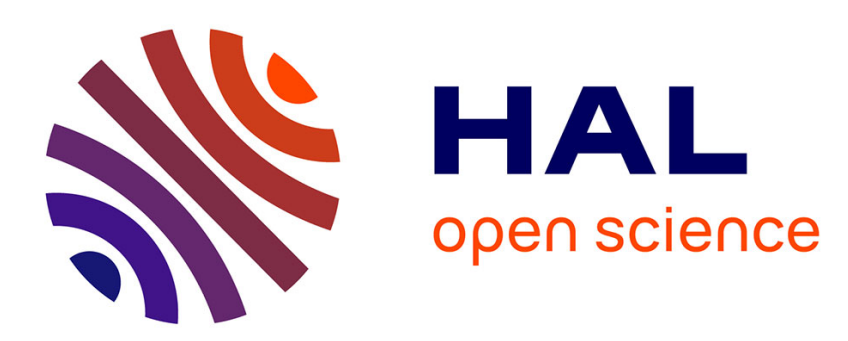

\title{
Le " patrimoine culturel du renne": pratiques touristiques et trajectoires nomades chez les Évenk de Chine (Mongolie-Intérieure)
}

\author{
Aurore Dumont
}

\section{- To cite this version:}

Aurore Dumont. Le " patrimoine culturel du renne" : pratiques touristiques et trajectoires nomades chez les Évenk de Chine (Mongolie-Intérieure). Autrepart - Revue de sciences sociales au Sud, 2016, 78-79 (2-3), pp.277-291. 10.3917/autr.078.0277 . halshs-02520137

\section{HAL Id: halshs-02520137 \\ https://shs.hal.science/halshs-02520137}

Submitted on 1 Apr 2020

HAL is a multi-disciplinary open access archive for the deposit and dissemination of scientific research documents, whether they are published or not. The documents may come from teaching and research institutions in France or abroad, or from public or private research centers.
L'archive ouverte pluridisciplinaire HAL, est destinée au dépôt et à la diffusion de documents scientifiques de niveau recherche, publiés ou non, émanant des établissements d'enseignement et de recherche français ou étrangers, des laboratoires publics ou privés. 


\title{
Le " patrimoine culturel du renne " : pratiques touristiques et trajectoires nomades chez les Évenk de Chine (Mongolie-Intérieure)
}

\author{
Aurore Dumont*
}

En République populaire de Chine, l'articulation entre tourisme et pratiques patrimoniales est un phénomène désormais bien connu et largement étudié, notamment dans le sud du pays où vit un grand nombre de populations dites minoritaires. Les régions du Nord-est chinois demeurent en revanche peu documentées, en dépit de l'intensification du tourisme et des campagnes de patrimonialisation depuis les années 2000. Région frontalière peuplée de diverses «minorités nationales ${ }^{1}$ » (shaoshu minzu), la préfecture de Hulunbuir ${ }^{2}$, dans la province autonome de Mongolie-Intérieure, illustre l'existence de nouvelles pratiques touristiques, susceptibles d'éclairer la dialectique de construction du «patrimoine culturel immatériel » (fei wuzhi wenhua yichan) chinois et des stratégies qu'elle implique. Les expériences individuelles et collectives mêlant différents types de tourisme (tourisme dit ordinaire, tourisme ethnique et plus récemment écotourisme) permettent d'interroger les interactions entre population chinoise majoritaire et groupes minoritaires, les modalités de création de lieux divers et les stratégies de légitimations identitaires. Tel est aussi le cas chez les Évenk du renne (xunlu ewenke), une petite communauté d'éleveurs de rennes dont le mode de vie reposait, voilà encore deux décennies, sur la combinaison de l'élevage mobile et de la chasse dans la taïga. En 2008, l'inscription de la «culture du renne » sur le répertoire national du «patrimoine culturel immatériel » chinois a succédé à la transformation du village et de certains campements nomades évenk en zones dédiées au tourisme estival. Les éleveurs de rennes et leurs troupeaux sont devenus le symbole de la « culture évenk », représentée dans le musée local et mise en scène lors de spectacles chorégraphiés, produisant des reconfigurations identitaires et spatiales inédites. Mais en contexte touristique, qu'en est-il de la mobilité, un paramètre

* Post doctorante, Centre for China Studies, The Chinese University of Hong Kong.

1. La République populaire de Chine est officiellement composée de cinquante-six «nationalités » (minzu) dont cinquante-cinq sont dites minoritaires (shaoshu minzu).

2. La préfecture de Hulunbuir est encerclée à l'est par la province du Heilongjiang, au nord-ouest par la Fédération de Russie, au sud-ouest par la République de Mongolie. 
essentiel pour les populations vivant de l'élevage pastoral ? Si la mobilité des éleveurs reste conditionnée par les besoins de leur économie domestique, elle est aussi une stratégie touristique récente : les Évenk modifient leurs trajectoires de nomadisation et adaptent leurs déplacements en fonction des besoins du tourisme estival.

La présente contribution prendra pour cas de figure les pratiques touristiques à l'œuvre chez les Évenk éleveurs de rennes, afin d'explorer les différents types de mobilité qu'elles entraînent. Après avoir exposé les politiques sédentaires et patrimoniales mises en place par les autorités régionales, notre propos s'articulera autour de deux axes. Le premier examinera les pratiques touristiques déployées autour de la « culture du renne ». On s'intéressera notamment à la compréhension de deux types de patrimoine de la «culture du renne »: sa mise en application par les autorités chinoises d'une part et sa perception par les Évenk d'autre part. Le second axe portera sur les diverses formes de mobilité effectuées par les Évenk entre les espaces nomade et sédentaire et leur logique organisationnelle.

\section{Les Évenk du renne : une mobilité pastorale en transition}

\section{L'économie domestique évenk}

Peuple toungouse ${ }^{3}$ d'Asie septentrionale, les Évenk éleveurs de rennes forment en Chine une des composantes de la « minorité nationale évenk ${ }^{4}$ » selon la nomenclature officielle. Au nombre de deux cent quatre-vingt-dix individus environ, ils sont les seuls à pratiquer ce type d'élevage dans le pays. Jusque dans les années 1960, leur mode de vie reposait sur la combinaison de l'élevage du renne et de la chasse, deux types d'activités nécessitant une utilisation extensive du territoire et une mobilité très soutenue. Les déplacements étaient cruciaux pour le bien-être du renne dont la nourriture saisonnière demandait un renouvellement régulier, et pour le chasseur, qui, soucieux des migrations et cycles reproductifs des espèces, alternait les lieux de chasse afin d'accroître ses chances de prises de gibier. Au début des années 1930, l'anthropologue Ethel J. Lindgren avait noté que la zone de nomadisation des Évenk s'étendait sur environ 7000 kilomètres carrés [Lindgren, 1938, p. 609]. L'hiver, la nomadisation avait lieu tous les deux ou trois jours contre dix à vingt en été [Kajgorodov, 1968, p. 126]. Outre leurs déplacements à dos de renne, les Évenk utilisaient la barque en bois de bouleau l'été et les skis fabriqués en bois de pin en hiver. Sur le plan matériel, le renne

3. Les Toungouses forment un ensemble de populations, dont les langues appartiennent à la branche toungouso-mandchoue de la famille linguistique altaïque. Ils occupent un vaste territoire couvrant la Sibérie, le nord-est de la Chine et le nord de la Mongolie. En RPC, les Toungouses sont composés des Mandchous (10 000 000), des Évenk (30 875), des Oroqen (8 200) et des Hezhe (4 200). Leur mode de vie varie d'une région à une autre. La taïga abrite des éleveurs de rennes, des pasteurs de chevaux, des chasseurs-pêcheurs ou encore des agriculteurs, tandis que la steppe fournit aux autres groupes des pâturages adaptés à l'élevage du gros bétail et à l'agriculture.

4. La «minorité nationale évenk» (ewenke shaoshu minzu) est composée de trois sous-groupes : les éleveurs de rennes qui vivent dans les zones forestières, les Solon et les Khamnigan, sous influence mongole, qui pratiquent l'élevage du gros bétail de type mongol dans la steppe. 
domestiqué était doté de multiples fonctions : celle d'animal de bât lors de la nomadisation ou de la chasse et celle de moyen de transport pour les hommes. Le renne domestique fournissait en outre du lait et une peau particulièrement solide, utilisée dans la confection d'habits et d'ustensiles d'usage courant. Sur le plan social et rituel enfin, le renne s'inscrivait dans un système d'échanges au sein de la communauté. Il apparaissait sous forme de don fourni par la famille du futur marié à celle de sa future épouse afin de sceller une alliance, ou pouvait être offert aux esprits lors de rituels chamaniques.

\section{Politiques chinoises de sédentarisation (1949-2003)}

Les politiques de sédentarisation et l'économie planifiée menées depuis la fondation de la République populaire de Chine en 1949 ont profondément altéré l'économie domestique et l'organisation sociale des Évenk. À partir des années 1950, la campagne de sédentarisation se concrétise par la création du « village ethnique évenk » (ewenke minzu xiang) doté d'infrastructures adaptées, selon la terminologie communiste, au «développement social et économique des nomades » : écoles, dispensaires, petits magasins. Cependant, l'élevage du renne nécessitant des déplacements fréquents, les autorités ont été très tôt confrontées à un dilemme : sédentariser la population et mettre fin à l'élevage du renne, ou bien tolérer les déplacements nomades (mais contrôlés) afin de conserver cette économie propre aux seuls éleveurs de rennes de Chine. S'il n'a pas réussi à sédentariser les Évenk, l'État a cependant lancé diverses politiques visant à les fixer sur un territoire délimité et contrôlable, entraînant ainsi une réduction des aires de nomadisation. Au début des années 1960, reconnaissant le potentiel économique des bois de renne, le gouvernement transforme l'élevage de rennes en petits troupeaux en un mode de production intensif. Le millier de têtes de rennes est collectivisé et chaque année les nomades vendent à l'État les bois de leurs animaux en échange de points de travail. Par ailleurs, les nomades doivent faire face à un accès plus difficile à leurs territoires de nomadisation, considérablement réduits en raison de l'exploitation industrielle de la région. La décollectivisation au début des années 1980 marque la fin de l'achat planifié par l'État et donne lieu à une restructuration conséquente des économies pastorales que les autorités souhaitent désormais transformer en productions commerciales. La politique centrale de «Développement du Grand Ouest» (Xibu dakaifa), lancée au début des années 2000, marque une phase de transition importante dans cette direction. Les campagnes de sédentarisation, la promotion du tourisme et la protection environnementale en constituent les axes majeurs. À une échelle locale, cette politique s'est concrétisée par la «migration écologique» (shengtai yimin) en 2003 des Évenk et de leurs troupeaux dans un nouveau village baptisé «Aoluguya », situé en périphérie de la ville de Genhe, et par l'interdiction de la chasse. En Chine comme ailleurs, le concept de «migration écologique » fait référence au déplacement organisé de populations humaines au bénéfice d'un écosystème. Bien qu'officiellement lancées au tout début des années 2000 afin d'enrayer la dégradation de l'environnement et la pauvreté dans les zones les plus fragiles du pays, 
les «migrations écologiques » sont pratiquées en Chine depuis les années 1980. Dans le nouveau village évenk, la proximité du milieu urbain inadapté aux besoins des rennes a conduit les autorités à concéder aux éleveurs le droit de retourner sur leurs campements. Aujourd'hui, les Évenk vivent entre leur village et leurs campements, situés à plusieurs dizaines, voire à des centaines de kilomètres du village. Appelé localement « être établi (sédentarisé) à un endroit sans y résider » (ding er bu ju), ce phénomène perdure depuis des décennies, et s'est accentué par le récent développement du tourisme. En 2008, les autorités régionales ont lancé un vaste projet touristique orienté vers la mise en valeur du renne, l'animal emblématique de la région. Inscrite sur la liste du «patrimoine culturel immatériel » chinois, la «culture du renne » (xunlu wenhua) est déployée autour de la construction imaginée ou réelle de différents espaces et personnages.

\section{La « culture du renne » : un « patrimoine culturel immatériel » sous l'égide des autorités locales (depuis 2007)}

\section{Création d'un « patrimoine culturel immatériel »}

«En République populaire de Chine, le "patrimoine culturel immatériel" occupe désormais une place centrale en tant que notion à même d'organiser la préservation des cultures traditionnelles » [Gros, 2012, p. 24]. Après avoir ratifié la Convention pour la sauvegarde du patrimoine culturel immatériel de l'Unesco en 2003, la Chine s'est engagée dans le recensement de son patrimoine culturel immatériel. Celui-ci recouvre des réalités diverses, de la conservation du patrimoine architectural urbain à travers la relecture de l'histoire [Bellocq, 2006, p. 24], à la revitalisation de certains rituels dans les régions minoritaires, en passant par la sauvegarde des arts populaires comme le papier découpé [Bodolec, 2012] ou la récupération d'anciennes «superstitions » [Gao, 2014]. Bien que la «culture du renne » ne soit pas officiellement inscrite dans un programme international de sauvegarde du patrimoine comme ceux de l'Unesco ${ }^{5}$, les autorités l'ont érigée en un patrimoine local. À la suite de la demande du gouvernement de Genhe, dont dépend administrativement le village évenk, les « coutumes de renniculture des Évenk » (ewenke xunlu xisu) ont été inscrites en 2008 sur la seconde liste ${ }^{6}$ de l'inventaire national du patrimoine culturel immatériel. Lesdites coutumes constituent un des éléments de l'inventaire chinois des pratiques culturelles censées être l'emblème de la culture populaire évenk. L' «art manuel du bois de bouleau » (huashupi shougong zhizuo jiyi) et la « danse chamanique » (saman wu) sont venus compléter cet inventaire national tandis que les « coutumes matrimoniales évenk » (ewenke hunsu), la «culture du renne » (xunlu wenhua), les «vêtements ethniques évenk » (ewenke minzu fushi) et d'autres «coutumes évenk » (ewenke chuantong minsu) ont été intégrés à l'inventaire régional du patrimoine culturel immatériel

5. Parmi les peuples toungouses de Chine, seul «l'art du conte Yimakan » des Hezhe (population de pêcheurs vivant dans le nord de la province du Heilongjiang) a été inscrit en 2011 sur la liste du patrimoine culturel immatériel de l'Unesco nécessitant une sauvegarde urgente.

6. La première liste date de 2006. 
[Ma, 2013]. Par ailleurs, quatre « représentants évenk de la transmission du patrimoine culturel immatériel évenk » ont été élus au niveau régional, chacun étant détenteur d'un domaine de spécialisation comme le chant, les instruments de musique ou encore la confection de vêtements. Ces anciens ont d'ailleurs participé, en coopération avec le bureau de la culture et les autorités locales, à la mise en patrimoine de certaines pratiques.

«Les politiques muséales et patrimoniales prennent la suite et épousent les logiques d'une longue histoire d'intervention étatique dans le domaine de la culture »[Trémon, 2012, p. 5]. Ceci est particulièrement vrai dans les régions peuplées de « minorités ethniques », dont certaines pratiques oubliées depuis longtemps ont été remodelées, parfois même inventées, dans le but de correspondre à la « culture traditionnelle » d'un groupe donné. Considérés comme des « coutumes populaires » dans les années 1990, les pratiques chamaniques, le chant et les danses évenk ont ainsi servi de support à l'invention d'une fête officielle évenk, le « Festival de Bon Augure » (sebin jie), instauré en 1994 et célébré chaque année le 18 juin. Le festival et son contenu ont été élaborés par l'Association de recherches sur les Évenk de Mongolie-Intérieure ${ }^{7}$ (Neimenggu ewenke zu yanjiuhui).

Parallèlement à la patrimonialisation de la «culture du renne », les autorités locales s'engagent dans un projet de développement touristique de grande envergure en 2007. Elles font appel à des consultants de l'agence finlandaise Pöyry, spécialisée dans le conseil et l'ingénierie, afin de reconfigurer le village d'Aoluguya sur le même modèle que les villages touristiques Sami ${ }^{8}$ en Finlande. Le but de cette coopération est de «préserver le patrimoine culturel et les moyens de subsistance traditionnels d'Aoluguya en transformant les anciennes compétences et le style de vie unique en un produit touristique » [Pöyry Consulting Company Limited, 2008, p. 7]. En 2008, le renne est décrété espèce protégée, puis devient l'emblème de la ville de Genhe et du village d'Aoluguya, renommé « village de la culture du renne » (xunlu wenhua zhi xiang). Dès lors, cette stratégie politique a justifié la construction d'espaces spécifiques et la mise en scène de personnages visant à développer le tourisme local dans une région où il était pratiquement inexistant, tout en valorisant le patrimoine de la «culture du renne ».

\section{Mise en scène de la « culture du renne » dans le village évenk}

Envisagée par les autorités locales dans ses dimensions à la fois matérielle et immatérielle, la « culture du renne » englobe un espace naturel particulier, la taïga, sa flore, le renne, et ses nomades, les Évenk. La configuration du nouveau village se situe à mi-chemin entre un village écologique et touristique, mêlant architecture contemporaine et reproduction d'un prétendu habitat nomade traditionnel. Il incarne un lieu singulier dont les habitants sont identifiés comme les « derniers

7. Fondée en 1984 et constituée d'intellectuels évenk (chercheurs, cadres, écrivains), l'association fait partie de ces instances bureaucratiques mobilisées pour la valorisation culturelle des minorités ethniques.

8. Population finno-ougrienne basée en Norvège, en Finlande, en Suède et au nord de la Russie, les Sami vivent traditionnellement de la pêche et de l'élevage de rennes. 
chasseurs et éleveurs de rennes de Chine » [Dumont, 2013, p. 271]. Pris en charge par un guide, les touristes chinois, majoritairement citadins et originaires de la Chine entière, se rendent à Aoluguya pendant la saison estivale de la mi-juin à la fin du mois de juillet. Leur trajectoire touristique débute dans le village où l'univers de « la culture du renne » se décline sous ses formes les plus diverses : musée de la «culture du renne », maisons et bâtiments écologiques en bois de style finlandais, habitat nomade transformé en aire de jeux pour les enfants et parc ethnique. Le musée ${ }^{9}$ expose les caractéristiques de la «culture du renne » que l'observateur peut facilement identifier : tente conique, objets en peau de renne ou en bois de bouleau, costume attribué à la dernière chamane disparue en $1993{ }^{10}$. Les représentations figées du musée sont ensuite mises en scène dans le parc ethnique, financé par les autorités locales, mais géré par un Évenk qui obtient une partie des bénéfices. Sorte de musée en plein air, « le camp touristique de la tribu primitive » (yuanshi buluo lüyoudian) emploie à la saison des éleveurs évenk ou bien des étudiants chinois déguisés en Évenk. Le décor naturel est associé à la mise en scène d'activités présentées comme «typiquement évenk ». Moyennant une somme de dix yuan $(1,40 €)$, le touriste peut obtenir chance et protection en tournant trois fois autour de l'«arbre rituel» (shenshu). Présentée comme une tradition chamanique évenk, il s'agit en réalité de l'adaptation du rituel de l' $o b o o^{11}$, pratiqué par les populations mongolophones des régions steppiques. Traditionnellement érigé sur les hauteurs, l'oboo est un monticule de pierres et de branchages dédié aux esprits locaux. Des rituels collectifs visant le bien-être de la communauté et la fertilité des troupeaux lui sont dédiés en été. Influencés par leurs voisins mongols à qui ils ont emprunté le rituel de l'oboo, les Solon et les Khamnigan, les deux autres sous-groupes de la « minorité nationale évenk », pratiquent le rituel de l'oboo. Après avoir paré l'oboo de rubans cérémoniels, les participants déposent des offrandes puis en font le tour trois fois dans le sens horaire. L'arbre rituel n'est cependant pas inconnu des Évenk du renne, bien au contraire. Considéré comme un arbre sacré, le bois de bouleau était autrefois utilisé par les chamanes et les Évenk pour réaliser différents types de rituels. Aujourd'hui perdue en Chine, l'offrande de rubans de couleurs aux arbres a été conservée chez les Évenk du Sud-est sibérien ${ }^{12}$. Elle est réalisée dans la forêt à des endroits précis tels les campements, les passages de cols difficiles, ou les traversées des rivières au cours tourmenté [Lavrillier, 2005, p. 317-318]. Dans le parc ethnique, la décoration de l'arbre et la circumambulation sont deux éléments empruntés au rituel de l'oboo. Cependant, pour les Évenk, l'existence passée d'arbres rituels dans leur culture peut justifier la présence d'une pratique certes modifiée, mais qui permet également de valoriser des pratiques anciennes.

9. Chaque espace est payant depuis 2012 : l'entrée au village, au musée et celle du parc ethnique. Toutefois, les touristes privilégient souvent un forfait comprenant toutes les entrées.

10. D'après certains éleveurs, il s'agirait d'une reproduction. Le véritable costume se trouverait dans un musée privé de la ville de Genhe.

11. Le rituel de l'oboo vient d'être inscrit (2016) sur la liste du patrimoine culturel immatériel national chinois.

12. Les Évenk de Russie forment avec ceux de Chine un même peuple. 
Le parcours du groupe de touristes s'achève dans la « zone de la tribu primitive » (yuanshi buluo qu) où le cadre de vie naturel du nomade est recréé : tente en peau de renne, Évenk (ou employés chinois) en costumes ethniques entourés de rennes. Dans ce décor construit et élaboré autour du «patrimoine culturel du renne », le personnage évenk correspond au nomade auquel l'imaginaire chinois l'a assigné. Pour les Évenk travaillant dans le parc ethnique, même remodelées, les activités et les représentations permettent aussi de populariser la «culture évenk » auprès des personnes qui ne soupçonnaient même pas l'existence d'un peuple éleveur de rennes.

Au départ limité à une dizaine de personnes par jour, le tourisme à Aoluguya s'est considérablement développé depuis 2012, tout comme les magasins de produits ethniques. Le choix des objets souvenirs était autrefois restreint : fabriqués par les locaux et vendus directement dans leurs maisons, ils consistaient principalement en des bois de rennes, des boîtes en bois de bouleau, et des sacs ou vêtements faits en peau de chevreuil ou de renne. Depuis l'engagement des autorités locales dans le tourisme, la palette de produits ethniques, plus diversifiée, est déployée autour de l'« art manuel du bois de bouleau », ou des «vêtements ethniques évenk », inscrits sur le patrimoine culturel immatériel. Si certains articles sont toujours confectionnés par les éleveurs, comme les objets en bois de bouleau, d'autres sont en revanche fabriqués dans des usines d'autres provinces de Chine, voire à l'étranger. Tel est le cas des tapis en peau de renne provenant de Finlande ou des pendentifs décoratifs fabriqués par les Évenk de Russie. La production de la plupart de ces objets souvenirs a été pensée par l'entreprise finlandaise Pöyry tandis que les commandes sont passées par les directeurs des magasins, la plupart des Chinois résidant dans le village. Ce commerce d'objets représente, avec l'entrée payante des différents sites, une part importante des revenus générés. La perception par les Évenk de ces objets souvenirs présentés comme ethniques diffère selon les uns et les autres. On peut cependant souligner que l'utilisation de matériaux et de techniques locaux (peaux de renne ou de chevreuil préalablement travaillées par une femme connaissant les techniques) est largement valorisée par la communauté évenk.

Au-delà des interactions produites entre hôtes et visiteurs, le tourisme déployé autour $\mathrm{du}$ «patrimoine culturel du renne» engendre des logiques de mobilité importantes entre le village et les campements. Encouragées par les autorités locales, certaines familles d'éleveurs ont choisi d'adapter leurs campements à la venue des touristes, en modifiant, entre autres, leurs parcours de nomadisation le temps d'un été.

\section{Trajectoires nomades}

\section{Détourner les trajectoires de nomadisation pour les touristes}

Lorsque le tourisme était marginal dans la région, les touristes limitaient leurs déplacements au sein du village. Le souhait des autorités d'offrir des activités diversifiées autour de la «culture du renne » a élargi les déplacements des touristes 
aux campements nomades. Jusqu'en 2011, ceux-ci demeuraient difficiles d'accès en raison de leur éloignement et de l'inexistence de transport. Les visiteurs souhaitant s'y rendre devaient se renseigner au préalable sur l'emplacement exact du campement, puis trouver un moyen de locomotion. Situés à une distance comprise entre une vingtaine et plus de deux cents kilomètres du village d'Aoluguya, les campements étaient alors au nombre de neuf. Quelle que soit la saison, le campement est appelé «point des chasseurs» (liemin dian) en chinois et «campement» (egdan) en évenk. Second lieu de vie des éleveurs après le village, le campement est essentiel pour la communauté évenk : c'est un espace de vie mettant en exergue leurs pratiques d'utilisation de la forêt pour les besoins de la chasse et de l'élevage. De plus, le campement est un espace détaché, spatialement et symboliquement, du centre administratif, laissant aux éleveurs une plus grande marge de manœuvre, notamment dans la gestion de leurs troupeaux et d'autres activités économiques annexes. Avant la «migration écologique » de 2003, les Évenk avaient une fréquence de nomadisation soutenue, changeant de campement chaque semaine, comme l'a relevé Tang au milieu des années 1990 [1998, p. 90]. Aujourd'hui, ils nomadisent chaque saison, soit environ quatre fois dans l'année. Le nombre de kilomètres effectués annuellement pour la nomadisation varie, en fonction des familles, entre trois et vingt kilomètres. La nomadisation est désormais réalisée à l'aide d'un camion. On notera que de l'autre côté de la frontière, les Évenk de Russie parcourent annuellement plusieurs milliers de kilomètres [Lavrillier, 2006, p. 5]. Outre le cycle annuel de nomadisation, les Évenk réalisent des trajets incessants entre le village et leurs campements pour répondre à des nécessités diverses : ravitaillement en nourriture, prise en charge des animaux lors de la mise bas, ou encore soutien logistique aux parents proches. Depuis les années 1980, les parcours et la fréquence de nomadisation ont été considérablement restreints : le développement des espaces sédentaires, la mécanisation et les injonctions extérieures sont les principales causes d'une réduction des aires de nomadisation observée un peu partout en Asie intérieure.

Si les Évenk nomadisent moins loin et moins fréquemment, ils sont en revanche beaucoup plus mobiles. Alors que la mobilité dictée par l'élevage est réduite, elle est plus flexible grâce à la faculté d'adaptation dont font preuve les éleveurs face à des situations nouvelles, dont le développement du tourisme. La saison estivale venue, certaines familles évenk réceptionnent les touristes sur leur campement. Cette nouvelle activité implique divers ajustements liés à la mobilité. Comment la mobilité pastorale est-elle devenue une composante des pratiques touristiques ? La taïga est aujourd'hui parcourue par les touristes à la saison estivale, contraignant les éleveurs à ajuster leurs stratégies de mobilité. Celle-ci offre une double lecture : la première concerne la modification des trajectoires de nomadisation estivale, la seconde englobe les trajets effectués par les éleveurs entre les espaces nomade et sédentaire pour les besoins du tourisme.

Accueillir des touristes sur son campement nécessite de détourner dans un premier temps sa trajectoire de nomadisation, puis de trouver un emplacement idéal. Toutefois, les Évenk ne sont pas les seuls à coordonner ces paramètres et doivent envisager 
diverses stratégies pour répondre aux exigences de l'élevage, du tourisme et de l'administration forestière. En temps normal, l'occupation et la gestion de l'espace nomade nécessitent la prise en considération de deux facteurs. Le premier, d'ordre temporel et spatial, est dicté par le milieu environnemental et les besoins du troupeau. Pour les éleveurs de renne, la saison estivale est une période importante dédiée à la traite des femelles et à la préparation des feux de fumée contre les moustiques. La végétation doit par conséquent être adaptée aux besoins nutritionnels des troupeaux. Idéalement, les Évenk privilégient des espaces en retrait des zones urbaines et des routes principales, donc éloignés du village, afin de protéger les rennes des dangers externes (passage de véhicules, présence de braconniers) et de leur fournir une végétation adaptée. La richesse des sols en lichen et la proximité d'une source en eau sont de première importance. Le second paramètre à respecter est un critère bureaucratique : l'espace de campement doit être choisi selon les délimitations territoriales imposées par le Département des forêts de la ville de Genhe (Genhe linye ju). La taïga est aménagée en neuf domaines forestiers délimités en routes principales, puis en embranchements. Bien que chaque famille organise différemment son cycle annuel de nomadisation sur un territoire délimité, le respect des règles territoriales est identique. Elles supposent de ne franchir ni les monts et les montagnes ni les vallées. En contexte touristique, ces paramètres spatiaux fonctionnent de manière opposée. Le campement estival doit être situé à moins d'une vingtaine de kilomètres d'Aoluguya et aux abords d'une des routes principales du domaine forestier, afin d'être le plus proche possible du village (moins d'une demi-heure en voiture). De plus, les chemins empruntés dans la taïga pour accéder au campement doivent permettre le passage de minibus ou de cars. L'emplacement doit ainsi combiner paramètres bureaucratiques, facilité d'accès, proximité du village et présence de sols adaptés pour les rennes. Trouver un espace en forêt approprié pour les rennes reste la tâche la plus difficile : la proximité urbaine n'est pas compatible avec une végétation de qualité. En juillet 2014, lors de notre dernière mission de terrain ${ }^{13}$, quatre campements sur un total de neuf étaient localisés, sous la forme de quatre points cardinaux autour du village, chacun étant situé à moins de vingt kilomètres d'Aoluguya.

Rapprocher son campement du village à la saison estivale peut porter préjudice aux troupeaux. Selon les dires des éleveurs pratiquant cette « mobilité touristique », ces aménagements estivaux sont dommageables pour le bien-être des animaux. La pauvreté de la végétation, la pollution, et le piétinement des espaces par les touristes contribuent à affaiblir les rennes. Les Évenk ayant fait ce choix évoquent la perspective de gains financiers et la période relativement courte de cette configuration qui compense ces aspects négatifs. Les éleveurs qui ne sont pas impliqués dans le tourisme formulent des arguments similaires pour expliquer leur choix de ne pas dévier leur trajectoire de nomadisation l'été.

13. Celle-ci a été réalisée en collaboration avec Semen Gabyshev, éleveur de rennes Évenk de Russie et Alexandra Lavrillier, maître de conférences à l'Université de Versailles Saint-Quentin-en-Yvelines, dans le cadre d'un projet collectif intitulé «Regards croisés ». Cette mission a bénéficié du soutien financier du groupement de recherche international «Nomadisme, sociétés et environnement en Asie centrale et septentrionale ». 
Schéma 1 - Disposition des campements des éleveurs de rennes à la saison touristique (juillet 2014)

Mangui

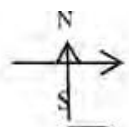

Alongbu

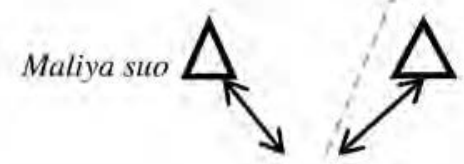

Lucia
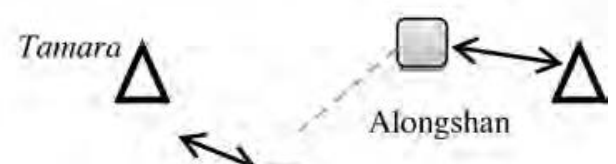

Alongshan

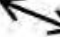

$\square_{\text {Jinhes }}$

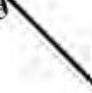

Dyawa

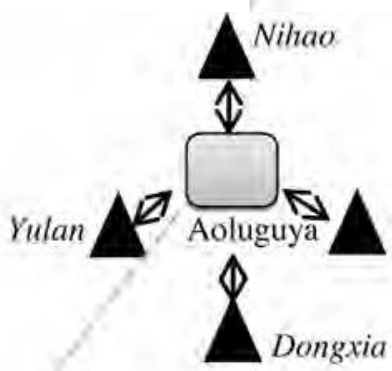

Wenqiang

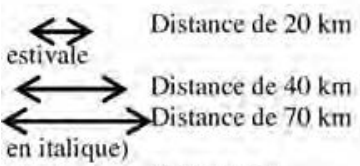

Bourg/ville

Aoluguya

Source : Schéma réalisé par Semen Gabyshev et Aurore Dumont. 
S'il est désormais très aisé pour un visiteur de se rendre sur un campement à la saison estivale, il est aussi facile pour les éleveurs de regagner le village. La venue régulière des touristes a en effet contribué à multiplier les déplacements des éleveurs. Lorsque le tourisme était peu développé, les éleveurs demeuraient l'été durant sur les campements et regagnaient le village une fois la saison achevée. Aujourd'hui, les trajectoires entre le campement et le village sont effectuées plusieurs fois par semaine, voire plusieurs fois par jour, en fonction de nécessités diverses, dont celles des touristes. Il peut s'agir par exemple de retourner au village pour aller chercher des produits spécifiques ou des souvenirs, ou bien de se rendre en ville pour acheter de la nourriture. Le village n'est pas seulement une entité administrative destinée à offrir selon l'expression chinoise consacrée, une «vie moderne » aux nomades. Il fait aussi figure de localité centrale pour les éleveurs. Le village occupe une position centrale dans les rapports qu'entretiennent les individus entre eux et avec la communauté dans laquelle ils s'insèrent. Les principales informations et décisions relatives à la vie du campement transitent par le village. Enfin, en tant que lieu de rassemblement touristique, le village est devenu un lieu incontournable pour les éleveurs engagés dans le tourisme. Ces trajets sont réalisés en fonction des moyens de locomotion disponibles : la moto personnelle si les biens à transporter sont légers, en taxi, ou en empruntant les voitures de tierces personnes, comme des chauffeurs de taxi.

Bien que les autorités locales jouent un rôle important dans le développement du tourisme local, notamment par l'intermédiaire de support matériel, dévier sa trajectoire de nomadisation pour attirer les touristes relève d'un choix personnel ou familial. Le campement nomade est habituellement composé d'une ou plusieurs familles nucléaires partageant la garde des troupeaux. Depuis le développement du tourisme, les campements se sont multipliés. L'éclatement des grands campements au profit de plus petites unités (une famille nucléaire au lieu de 2 ou 3, il s'agit aussi parfois de familles divisées) témoigne de la volonté des Évenk de conserver les revenus touristiques au sein d'un noyau familial restreint. Ce facteur est renforcé par l'économie domestique évenk qui requiert une coopération régulière dans les activités d'élevage et de chasse, rendue indispensable par les distances importantes séparant le village des campements. Plus concrètement, le réseau familial est sollicité en fonction des activités de l'élevage : pour la naissance des animaux, la coupe des bois de rennes, etc. De la bonne coopération des membres d'une même famille élargie dépend donc le bien-être du troupeau et depuis quelques années, du bon fonctionnement du tourisme. D'après les informations d'une de mes informatrices, à l'été 2015, les campements sont au nombre de quinze environ, chacun souhaitant bénéficier de revenus complémentaires. Le tourisme représente un supplément financier bienvenu dans une localité où les principales ressources dépendent des aides gouvernementales, des bois de rennes et de la vente illégale des produits de la chasse. Jusqu'en 2012, les autorités locales achetaient les bois de rennes à chaque éleveur, constituant leur principale source de revenus. Après cette date, les autorités locales ont décidé d'assouplir cette règle : ceux qui le souhaitent 
peuvent continuer de vendre leurs bois de rennes aux autorités locales, ou bien les vendre librement, notamment aux touristes.

\section{Le patrimoine culturel immatériel du renne sur les campements}

Dans le village d'Aoluguya, les autorités ont créé un patrimoine culturel du renne décliné dans divers lieux. Comment ce patrimoine est-il mis en valeur sur les campements nomades afin de répondre aux attentes des touristes ? Si les activités et les lieux proposés sont moins diversifiés que dans le village, sur leurs campements, les Évenk possèdent en revanche deux éléments phares de la « culture du renne »: leurs troupeaux de rennes et l'habitat nomade.

Figure 1 - Habitats nomades - campement dans la région de Genhe

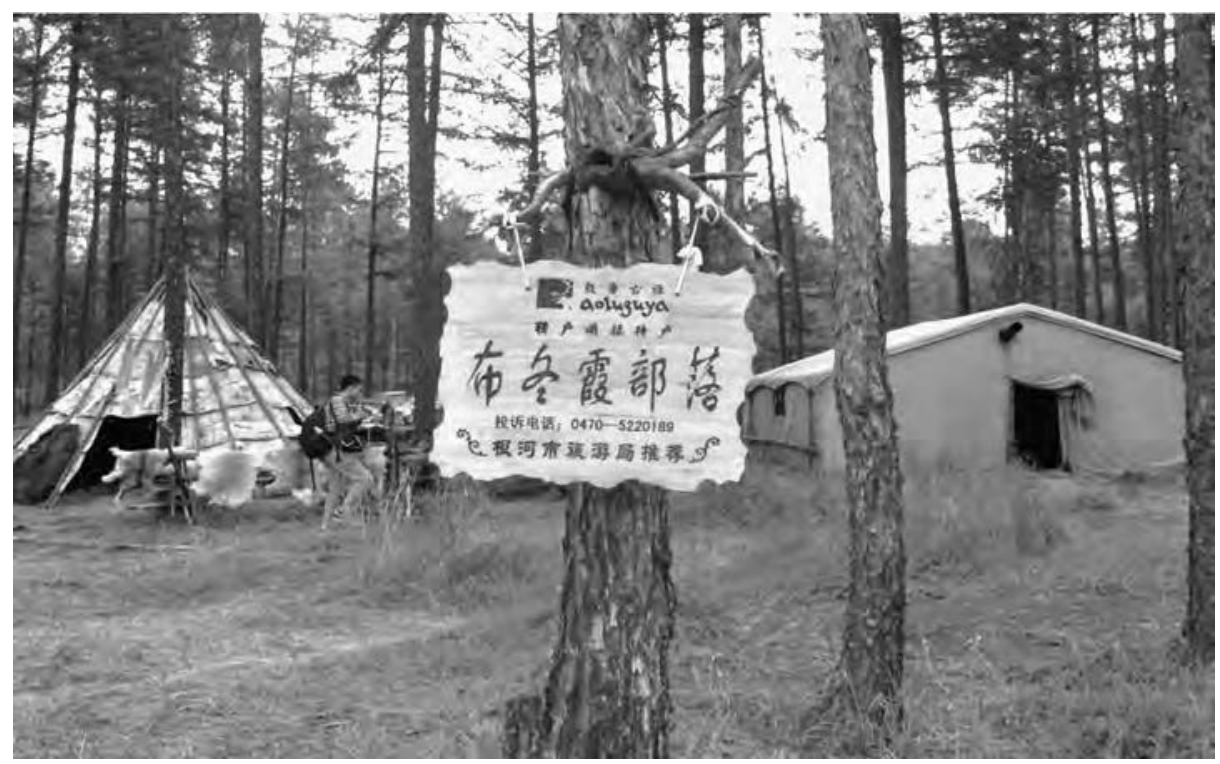

Source : Aurore Dumont (juillet 2014).

Dans le cadre de la politique de modernisation des campements, le matériel fourni par les autorités locales aux éleveurs a évolué : l'ancienne tente conique a été remplacée par des tentes rectangulaires en toile plus solide, tandis que les panneaux solaires permettent de visionner la télévision. Depuis 2011, le développement du tourisme a entraîné la réapparition des anciennes tentes coniques, jugées plus authentiques pour représenter l'habitat nomade. Le changement le plus significatif concernant la tente est la disparition de sa fonction d'habitation. L'intérieur dépouillé de la tente conique n'a désormais qu'un statut utilitaire : on y range les affaires d'hiver ou d'été pour la prochaine saison et tout ustensile invulnérable au froid ou à la chaleur. 
Figure 2 - Touristes sur un campement

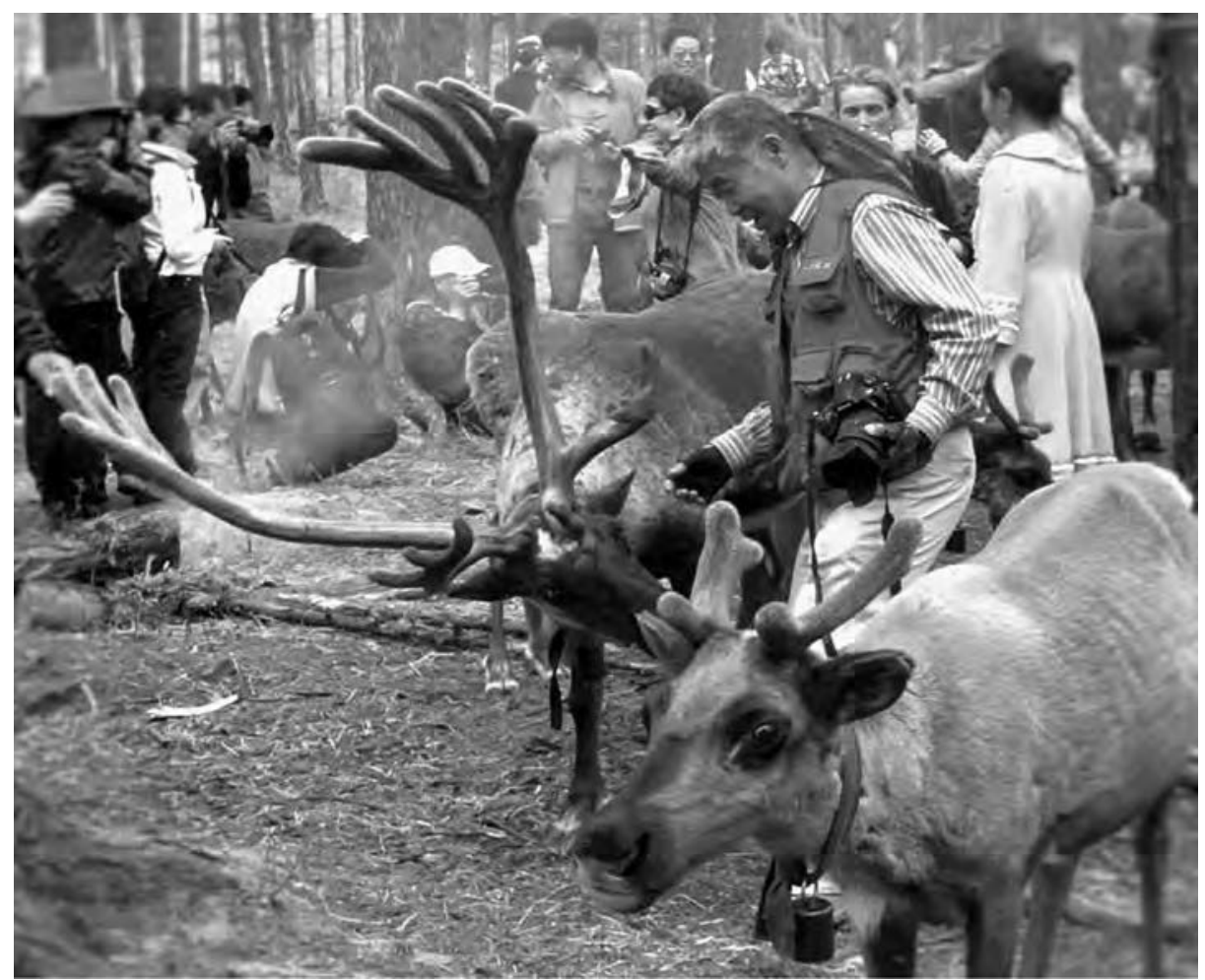

Source : Aurore Dumont (juillet 2014).

Les touristes ne restent en général pas plus d'une heure, et photographient les rennes et les tentes coniques contre une forte somme. Sur le campement, la « culture du renne » est limitée à la prise de photographies des rennes, et parfois des Évenk, qui jouent le jeu en revêtant leurs costumes ethniques. En revanche, tout le savoir-faire ainsi que les techniques d'élevage et de chasse, qui sont de première importance pour les Évenk, ne sont ni montrés ni expliqués. Entre juin et août, lorsque les moustiques apparaissent, les hommes construisent des feux de fumée au centre du campement destinés à protéger les rennes, c'est également la saison de la collecte des champignons, des réparations et des constructions des structures de tente. Ces activités ne semblent pas entrer dans le panel des activités dédiées aux touristes. De plus, les Évenk conservent certains espaces à l'abri des touristes. En effet, l'espace nomade est constitué d'un campement (regroupement sur une zone donnée d'une ou plusieurs familles nucléaires ou présence d'une personne seule), mais également de son environnement le plus proche : terrains de chasse et pâturages. Par ailleurs, un grand nombre d'espaces vierges, c'està-dire dépourvus de numéros d'occupation humaine sont utilisés par les Évenk pour l'élevage et la chasse. Ces espaces sont dotés de marques visibles et invisibles 
(en tout cas aux yeux occidentaux ou chinois) formant un jeu de repères spatiaux à partir desquels les Évenk s'orientent : c'est un espace parcouru, dont les éleveurs sont familiers. Les Évenk ont une connaissance vaste et globale de cet espace qu'ils parcourent pour les besoins de l'élevage et de la chasse. Ils en connaissent abris et ressources et les potentiels dangers. Ainsi, cet espace n'est jamais montré aux touristes, qui restent toujours dans une zone circonscrite. Liu a montré comment les Wa, pour échapper aux touristes, ont «créé leur propre espace à l'écart du village en coulisses où ils continuent leurs pratiques rituelles et sociales loin des touristes » [2013, p. 179]. Les Évenk font de même : certains gardent un espace sur leur campement, tandis que d'autres décident de ne pas accueillir de touristes sur leur campement et restent donc à l'écart dans la forêt, le temps d'un été.

\section{Conclusion}

Dans la région de Hulunbuir où vivent les éleveurs de rennes, la mise en patrimoine de la «culture du renne » par les autorités locales combinée au développement du tourisme a reconfiguré les espaces de vie des éleveurs. Le village est désormais façonné en lieux dédiés aux spécificités de la «culture du renne » où interagissent les Évenk et les touristes. Jusque-là laissés à l'écart du tourisme, certains campements nomades sont désormais des sites touristiques à la saison estivale. Cette nouvelle configuration engage certains éleveurs à détourner leur trajectoire estivale de nomadisation et à accentuer leur mobilité. Tout en demeurant une nécessité pastorale, la mobilité des éleveurs devient ainsi une stratégie pour bénéficier des retombées économiques du tourisme. Par ailleurs, la « culture du renne » est perçue différemment par les autorités chinoises et par les Évenk : alors que les premiers construisent et inventent des traditions perdues, les seconds peuvent jouer, mais peuvent aussi conserver leurs techniques et leurs pratiques d'élevage comme patrimoine culturel intouchable par les touristes.

Inscrit dans la valorisation du patrimoine culturel immatériel, le tourisme local à Aoluguya est présenté par les autorités locales comme un moyen d'intégrer la population locale dans l'expansion économique. Or, le tourisme est souvent appréhendé comme potentiellement néfaste pour le patrimoine [Boullosa-Joly, 2010, p. 103]. À Aoluguya, certaines familles profitent périodiquement des retombées économiques du tourisme. Le succès rencontré ces deux dernières années a conduit les autorités à réfléchir à d'autres formules touristiques non limitées à la période estivale. Le tourisme des glaces, déjà plus ou moins manifeste dans les zones steppiques de la région, pourrait rapidement voir le jour et produire de nouvelles dynamiques socio-économiques. Ces pistes permettront, dans les années à venir, de nous renseigner plus en détail sur l'évolution des pratiques touristiques et de la place des populations autochtones dans l'économie locale. 


\section{Bibliographie}

BELLOCQ M. [2006], « La préservation du patrimoine culturel en République populaire de Chine : pour quelle mémoire? », Perspectives chinoises, $\mathrm{n}^{\circ}$ 96, p. 24-34.

Bodolec C. [2012], « The chinese paper-cut : from local inventories to the Unesco representative list of the intangible cultural heritage of humanity », in BENTIX R., EGGERT A. (dir.), Heritage regimes and the State, Göttingen, Göttingen University Press, p. 249-264.

BoullosA-Joly M. [2010], «Tourisme, patrimonialisation et politique : un cas d'école : "la fête nationale de la Pachamama" (Nord-Ouest argentin) », Cahier des Amériques Latines, $\mathrm{n}^{\circ} 65$, p. $103-120$.

Dumont A. [2013], «L'écotourisme chez les Évenks du renne : de nouvelles relations entre nomades et sédentaires en Chine », in Stepanoff C., Ferret C., Lacaze G., Thorez J. (dir.), Nomadismes d'Asie centrale et septentrionale. Sociétés, mobilités et environnement, Paris, Armand Colin, p. 273-275.

GaO B. [2014], « How Does Superstition Become Intangible Cultural Heritage in Postsocialist China ?», Positions : Asia Critique, vol. 22, n 3, p. 551-572.

Gros S. [2012], «L'injonction à la fête. Enjeux locaux patrimoniaux d'une fête en voie de disparition », Gradhiva, n 16, p. 25-43.

Kajgorodov A. M. [1968], «Evenki v Trehreč'e. (Po ličnym nabljudenijam)» [Les Évenk de la région des Trois Rivières. (Observations personnelles)], Sovetskaja Etnografija, $\mathrm{n}^{\circ} 4$, p. 123-131.

LaVRILlier A. [2005], Nomadisme et adaptations sédentaires chez les Évenks de Sibérie postsoviétique : "jouer » pour vivre avec et sans chamanes, thèse de doctorat, vol. 2, Paris, École pratique des hautes études.

LAVRILLIER A. [2006], «S'orienter avec les rivières chez les Évenks du Sud-Est sibérien. Un système d'orientation spatial, identitaire et rituel », Études mongoles et sibériennes, centrasiatiques et tibétaines, $\mathrm{n}^{\circ}$ 36-37 : https://emscat.revues.org/779 (page consultée le 29 janvier 2016).

LINDGREN E. J. [1938], « An example of culture contact without conflict : Reindeer Tungus and Cossacks of North-Western Manchuria », American Anthropologist, New Series, vol. 40, $\mathrm{n}^{\mathrm{o}} 4$, p. 605-621.

LIU T., [2013], « Re-constructing cultural heritage and imagining Wa Primitiveness in the China/ Myanmar Borderlands », in Blumenfield T., Silverman H. (dir.), Cultural heritage politics in China, New York (N. Y.), Springer, p. 161-184.

MA K. [2013], «Guanyu Aoluguya Ewenke minzu wenhua chuancheng yu fazhan de diaoyan baogao » [Rapport d'enquête concernant le développement et la transmission de la culture de la minorité évenk d'Aoluguya], Hulunbei'er ganbu jiaoyu zai xian, octobre 2013: http://hlbe.jy365.net/Article/article.aspx?id=55 (page consultée le 10 janvier 2016).

PÖYRY CONSUlting COMPANY Limited [2008], rapport non publié, Aoluguya Tourism Master Plan.

TANG G. [1998], « Ewenke zu de xunlu wenhua » [La culture du renne des Évenk], Heilongjiang minzu congkan, $\mathrm{n}^{\circ} 2$, p. 90-94.

TRÉMON A.-C. [2012], «Introduction : l'État au musée. Politiques muséales et patrimoniales dans le monde chinois contemporain », Gradhiva, n ${ }^{\circ} 16$, p. 4-21. 